\title{
Extraction of 2,3-Butanediol with Aqueous Two-Phase Systems Formed by Water-Miscible Organic Solvents and Inorganic Salts
}

\author{
Michiaki MATSUMOTO, ${ }^{*}$ Ryosuke OKUNO and Kazuo KONDO \\ Department of Chemical Engineering and Materials Science \\ Doshisha University, Kyotanabe, Kyoto 610-0321 Japan \\ (Received January 13, 2014; Accepted February 27, 2014)
}

2,3-Butanediol is one of the bulk chemicals that exhibits a wide range of potential uses in cosmetics and transport fuels as well as being a precursor of synthetic rubbers. During the last few decades, considerable efforts have been made to improve the production of 2,3-butanediol from fermentation. However, major difficulties still exist in downstream processing because 2,3-butanediol has a high boiling point and a high affinity for water. In this study, aqueous two phase systems composed of water-miscible solvents and salts could be used to extract 2,3-butanediol from a model solution. We used $t$-butanol, tetrahydrofuran and 2-propanol as water-miscible solvents, and dipotassium hydrogen phosphate, tripotassium phosphate, potassium carbonate, potassium fluoride and tripotassium citrate as salts. The phase separation abilities of water-miscible solvents and the salting-out abilities of salts were evaluated by the difference in the binodal curves and salting-out of 2,3-butanediol. $t$-Butanol and tetrahydrofuran showed high phase separation abilities, and potassium carbonate showed as high a salting-out ability as conventional phosphate salts. The concentration in the top phase and recovery ratio of 2,3-butanediol reached $184.3 \mathrm{~g} / \mathrm{L}$ and $92.2 \%$, respectively, when the system was composed of tetrahydrofuran and potassium carbonate. This process provided the possibility of a simple and economical process for the separation of 2,3-butanediol from fermentation broth.

\section{Introduction}

2,3-Butanediol (2,3-BD), which is a precursor of 1,3-butadiene, has been used as an intermediate in synthetic rubber. Recently, 2,3-BD with a calorific value of $27.2 \mathrm{~kJ} / \mathrm{g}$ compares favourably with ethanol $(29.1 \mathrm{~kJ} / \mathrm{g})$ and methanol $(22.1 \mathrm{~kJ} / \mathrm{g})$ for use as a liquid fuel or fuel additive [1]. Although 2,3-BD was produced by a petroleum-based chemical synthesis route, in recent times sustainable bio-chemicals produced from renewable resources have been paid more attention as fossil fuel resources become increasingly scarce. The alternative route utilizing biomass is also of keen interest in 2,3-BD production. Therefore, studies for improving the production of 2,3-BD by fermentation such as strain screening and optimization of fermentation condition, have significantly increased [2]. Compared with these efforts devoted to upstream processing, similar efforts for downstream processing are just beginning. Due to the high boiling point $\left(183-4^{\circ} \mathrm{C}\right)$ and high hydrophilicity of $2,3-\mathrm{BD}$, recovery from fermentation broths becomes a vital factor for the industrial production of 2,3-BD. The cost of the separation process using distillation techniques for 2,3-BD is reported to be more than half of the production cost [3]. The 
development of an efficient and economic recovery process is required to improve the economics of the production process based on the biomass route. Steam stripping, extraction, pervaporation and vacuum distillation combined with alcohol precipitation have been proposed as separation methods [3,4]. Compared with other separation techniques, extraction is considered to posses several advantages, such as large throughput and low energy consumption. Solvent extraction with water-immiscible organic solvents (physical extraction), such as oleyl alcohol, 1-butanol and isobutanol produces low partition coefficients due to the high hydrophilicity of 2,3-BD [3, 5-8]. One way of improving the solubility in the organic phase is the conversion of 2,3-BD to hydrophobic compounds without hydroxyl groups using chemical reactions (reactive extraction) such as esterification with boronates [9] and acetalization with aldehydes [10-13]. An alternative way is to use an aqueous two-phase extraction system, which has been widely applied in the separation of biomacromolecules, such as proteins and nucleic acids because of its simplicity, low energy consumption, and ease in scaling up [14,15]. Ghosh and Swaminathan [16] reported extraction of 2,3-BD in a PEG-dextran aqueous two-phase system (ATPS). However, traditional ATPSs have been rarely used on a large scale for the production of cheap and bulk chemicals due to the high cost of polymers and the difficulty in isolating the extracted molecules from the polymer phase by back extraction [3].

In recent years, an ATPS formed by a salt/water-miscible alcohol, as an alternative to conventional ATPSs using polymers, has been afforded increasing attention since this technique has advantages of easy product and alcohol recovery, and low cost. ATPSs with a salt/water-miscible alcohol have been applied to the separation of 2,3-BD [17-20]. In these papers, ethanol and isopropanol as water-miscible alcohols, and dipotassium hydrogen phosphate and ammonium sulfate as inorganic salts were used. $\mathrm{Wu}$ et al. [21] employed the dipotassium hydrogen phosphate/1-butanol system for the extraction of 2,3-BD, although 1-butanol is not fully water-miscible.

In this study, we systematically investigated the effects of salts and water-miscible solvents including solvents other than alcohol to the extraction of 2,3-BD using the ATPS method with a salt/water-miscible solvent.

\section{Experimental}

\subsection{Preparation of phase diagram}

The binodal curves were determined by the cloud point method. $\mathrm{A}_{2} \mathrm{HPO}_{4}$ solution of known concentration was placed in a $100 \mathrm{~mL}$ conical flask and hydrophilic organic solvents (methanol $(\mathrm{MeOH})$, ethanol (EtOH), 1-propanol (1-ProOH), 2-propanol (2-ProOH), $t$-butanol $(t-\mathrm{BuOH})$, tetrahydrofuran (THF)) were added drop-wise to the flask until the clear solution turned turbid or two phase systems were formed. Then, de-ionized water was added drop-wise to the flask to obtain a clear one phase system and more hydrophilic organic solvents were added again to produce two phase systems. The composition of this mixture was noted and the experiments were repeated to obtain the binodal curve.

\subsection{Salting out experiment}

A certain amount of the salts $\left(\mathrm{K}_{2} \mathrm{HPO}_{4}, \mathrm{~K}_{3} \mathrm{PO}_{4}, \mathrm{~K}_{2} \mathrm{CO}_{3}, \mathrm{KF}, \mathrm{K}_{3} \mathrm{C}_{6} \mathrm{H}_{5} \mathrm{O}_{7}\right)$ was added to an aqueous solution of $18 \mathrm{~mL}$ including 2,3-BD $(50 \mathrm{~g} / \mathrm{L})$ in a graduated test tube. The concentrations of the salts were adjusted to 50 or $100 \mathrm{~g} / 100 \mathrm{~g}$-water. The solutions were mixed thoroughly and left standing for more than 6 $\mathrm{h}$ in a thermostated bath at $25^{\circ} \mathrm{C}$ to form the two phases. The volumes of the salted-out (top) and bottom 
phases were recorded. The concentrations of 2,3-BD and the water contents in both phases were analyzed by HPLC and Karl Fischer's method. The recovery ratio $(R)$ of 2,3-BD was defined as;

$$
R[\%]=\frac{C_{T} V_{T}}{C_{0} V_{0}} \times 100
$$

where $C$ and $V$ are the concentration of 2,3-BD and the solution volume respectively, and subscripts $\mathrm{T}$ and 0 denote the top phase and initial state.

\subsection{Aqueous two-phase extraction experiment}

Solid inorganic salts and $4 \mathrm{~mL}$ of water-miscible organic solvents were added into the $4 \mathrm{~mL}$ solution including 2,3-BD $(50 \mathrm{~g} / \mathrm{L})$ to form the ATPS consisting of 25-150 g-salt/100 g-water. The solution was mixed thoroughly and left standing for more than $6 \mathrm{~h}$ in a thermostated bath at $25^{\circ} \mathrm{C}$. The volumes of the top and bottom phases were recorded. The concentrations of 2,3-BD and the water contents in both phases were analyzed by HPLC and Karl Fischer's method. For a comparison, similar experiments were conducted with the water-immiscible organic solvents.

\section{Results and Discussion}

3.1 Phase diagram for the aqueous two phase system consisting of a water-miscible organic solvent and dipotassium hydrogen phosphate

Figure 1 shows the effects of water-miscible solvents on the binodal curves of the $\mathrm{K}_{2} \mathrm{HPO}_{4} /$ solvent ATPS at $25^{\circ} \mathrm{C}$ plotted as mass fractions. The closer the binodal curves are to the coordinates origin, the less the amount of solvent required for the formation of the ATPS under the same concentration of salt. From the figure, the phase separation abilities of solvents are in the order THF $>t-\mathrm{BuOH}>1-\mathrm{ProOH}$ $>2-\mathrm{ProOH}>\mathrm{EtOH}>>\mathrm{MeOH}$. Although the phase separation ability of 1-ProOH is higher than that of 2-ProOH, which is in accordance with a previous paper [22], the boiling point of $1-\mathrm{ProOH}\left(97.2^{\circ} \mathrm{C}\right)$ is considerably higher than those of 2-ProOH $\left(82.4^{\circ} \mathrm{C}\right)$, $t$-BuoH $\left(82.4^{\circ} \mathrm{C}\right)$ and THF $\left(65.4^{\circ} \mathrm{C}\right)$. Therefore, in the ATPS distribution experiments, 2-ProOH, $t-\mathrm{BuOH}$ and THF were used. Previously, THF was used as the

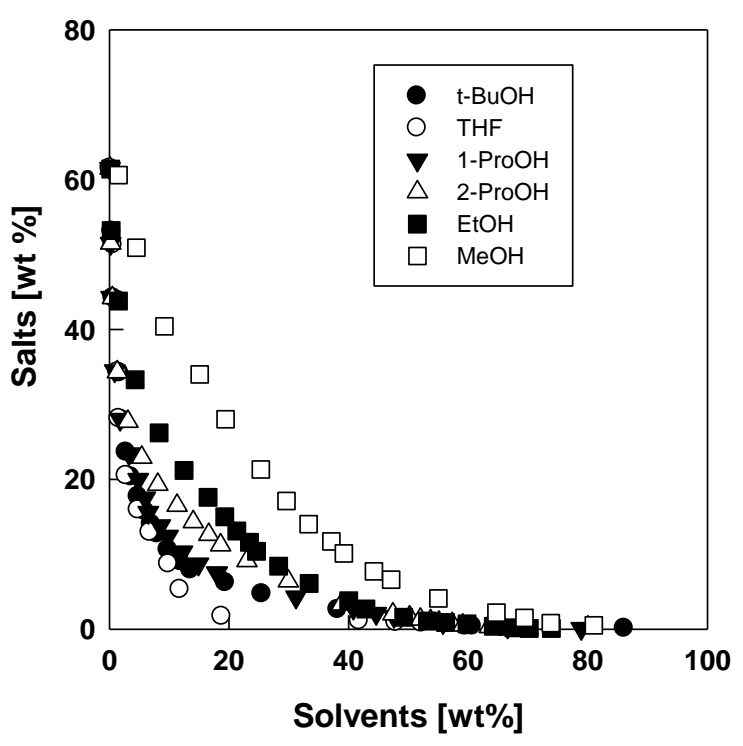

Figure 1. Effect of solvents on the binodal curves at $298 \mathrm{~K}$

solvent for the ATPS formed on using an ionic liquid as a salting out agent [23].

\subsection{Salting-out of 2,3-butanediol}

Table 1 shows the effect of salts on the salting out of 2,3-BD. In the table, although the concentration of 2,3-BD and water content in the top phase were measured separately by HPLC and the Karl Fisher method, it was found almost to satisfy the mass balances in all cases. The phase separation caused by salting-out occurred when the concentrations of $\mathrm{K}_{2} \mathrm{HPO}_{4}, \mathrm{~K}_{3} \mathrm{PO}_{4}, \mathrm{~K}_{2} \mathrm{CO}_{3}$ and $\mathrm{KF}$ were 100 g-salt/100 g-water. Under the same condition for $\mathrm{K}_{3} \mathrm{C}_{6} \mathrm{H}_{5} \mathrm{O}_{7}$, the phase separation was not observed. As 
reported previously [22], the salting out ability of $\mathrm{K}_{3} \mathrm{C}_{6} \mathrm{H}_{5} \mathrm{O}_{7}$ was lower than those of the others.

When considering separations with ATPSs, it is desirable to reduce the water contained in the extracted phase to make evaporation of the solvent and recovery of the desired product after the extraction process easy. However, lower water contents tended to depress the recovery ratio and the salting-out effect by salts only was insufficient for the recovery of 2,3-BD.

Table 1. Effect of salts on salting-out of 2.3-butanediol.

\begin{tabular}{lccc}
\hline \multicolumn{1}{c}{ Salts* } & $2,3-\mathrm{BD}[w \mathrm{wt} \%]$ & $R[\%]$ & Water [wt.\%] \\
\hline $\mathrm{K}_{2} \mathrm{HPO}_{4}$ & 71.3 & 67.8 & 30.6 \\
$\mathrm{~K}_{3} \mathrm{PO}_{4}$ & 76.3 & 54.5 & 18.2 \\
$\mathrm{~K}_{2} \mathrm{CO}_{3}$ & 83.7 & 44.9 & 16.6 \\
$\mathrm{KF}$ & 74.8 & 36.0 & 23.8 \\
\hline
\end{tabular}

*Salt concentrations are $100 \mathrm{~g}$-salt/100 g-water.

\subsection{Extraction of 2,3-butanediol with aqueous two phase systems}

Figures 2-4 show the partition behaviors of 2,3-BD in 2-ProOH, $t-\mathrm{BuOH}$ and THF/salts aqueous two phase systems. Figure 2 and 4 show that the 2,3-BD concentrations in the top phase increased and the water contents in the top phase decreased with increasing salt concentrations in all cases. From Figure 2, the 2,3-BD concentrations in the case of 2-ProOH were lower than those for the other solvents because of its low phase separation ability as shown in Figure 1. From Figure 3, solvents had no effect on the recovery ratio. As is evident from Figure 4, in the case of 2-ProOH which has a low phase separation ability, more water was distributed to the top phase compared with the other solvents. 2,3-BD together with water is considered to move to the top phase due to the high affinity between 2,3-BD and water. These results suggest that the use of solvents with a low capacity for phase separation causes the distribution of water to the top phase and this is considered economically undesirable for the required evaporation of the solvent after the aqueous two phase extraction process.

Salts with a high salting-out ability as expected from Table 1 showed high concentrations of 2,3-BD in the top phase. The highest recovery ratio of 2,3-BD, $96.5 \%$, was obtained by using $\mathrm{K}_{2} \mathrm{CO}_{3}$ as the salt and THF as the solvent. In that case, the 2,3-BD concentration obtained in the top phase was $48.2 \mathrm{~g} / \mathrm{L}$ and almost quantitative recovery of 2,3-BD was achieved.

In the above experiments, initially an aqueous solution of $4 \mathrm{~mL}$ and $4 \mathrm{~mL}$ of solvent were used. To enrich 2, 3-BD, we examined the effect of the initial amount of solvent added to the ATPS system consisting of THF or $t-\mathrm{BuOH}$ as the solvent and $\mathrm{K}_{2} \mathrm{CO}_{3}$ (50 or $100 \mathrm{~g} / 100 \mathrm{~g}$-water) as the salt as shown in Figures 5 to 7. From Figure 5, the concentration of 2,3-BD in the top phase increased with a decrease in the initial volume of the solvent and the highest concentration in the top phase was $184.3 \mathrm{~g} / \mathrm{L}$ when the $\mathrm{K}_{2} \mathrm{CO}_{3}$ concentration is $100 \mathrm{~g} / 100 \mathrm{~g}$-water and $1 \mathrm{~mL}$ of THF was added. The 2,3-BD concentration in the top phase was 3.7 times that in the initial feed phase, although the recovery ratio slightly decreased to $92.2 \%$. This makes application of an ATPS consisting of a water-miscible solvent and a salt to the separation process of 2,3-BD in the fermentation liquor process appear attractive, because the proposed ATPS can lead to simplification and reduction of the solvent to be removed in downstream processing. 


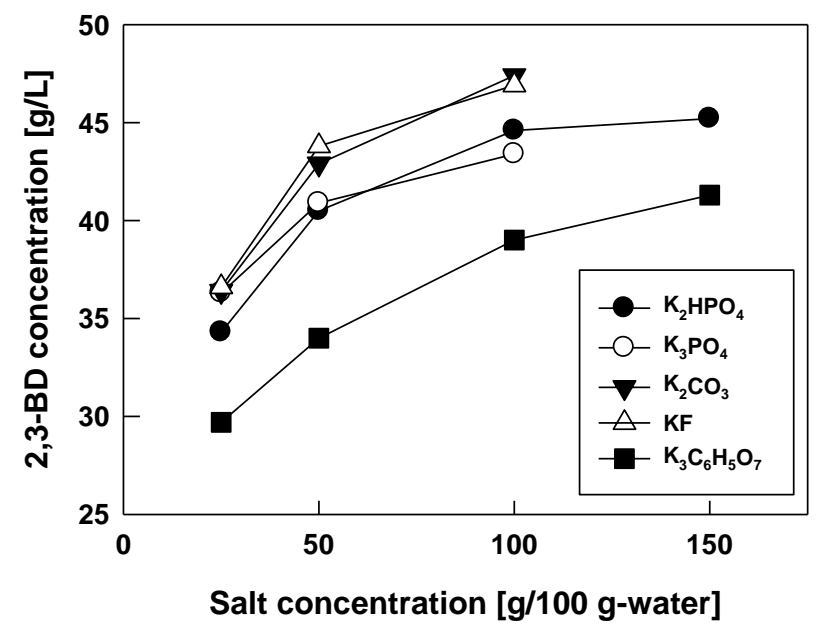

a. $t$-BuOH

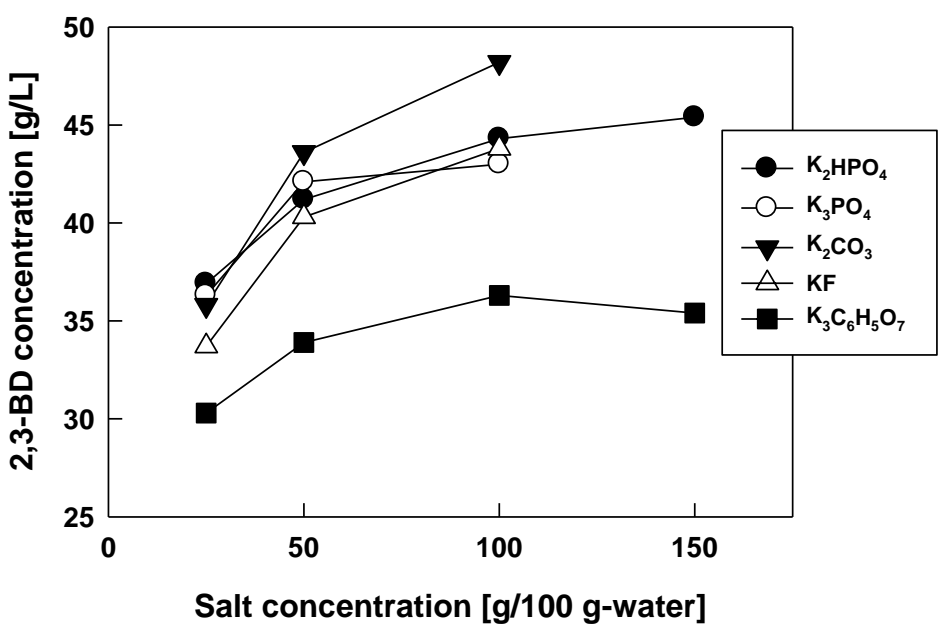

b. THF

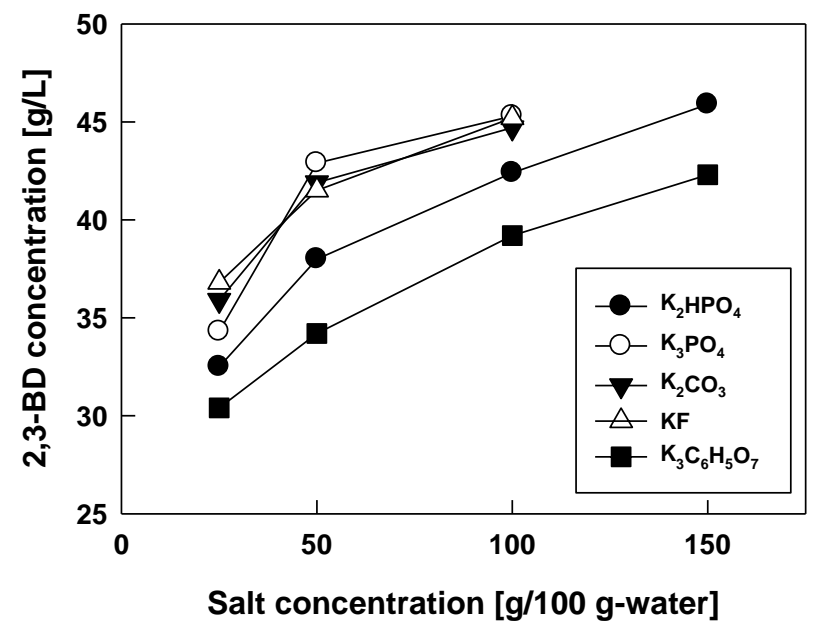

c. 2-ProOH

Figure 2. 2,3-BD Concentration in the top phase of the ATPS 


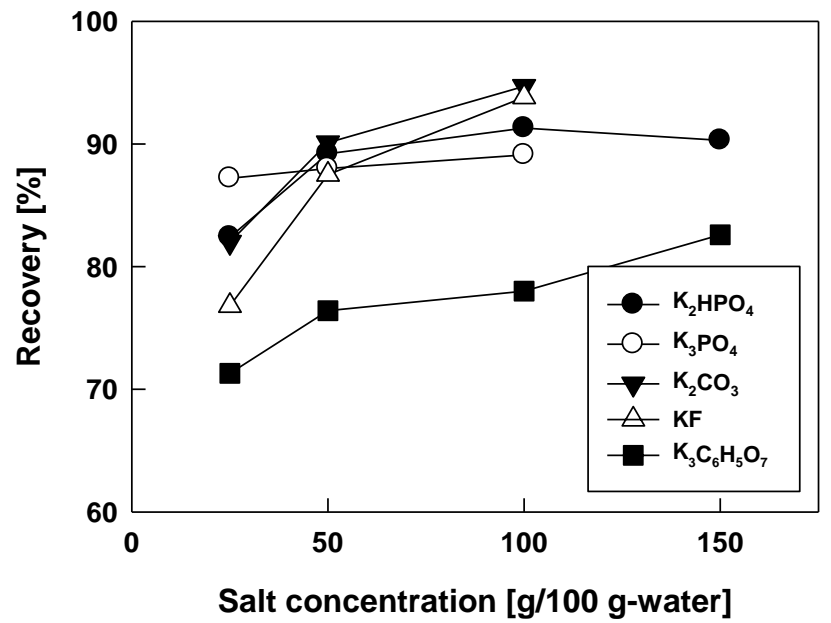

a. $t$-BuOH

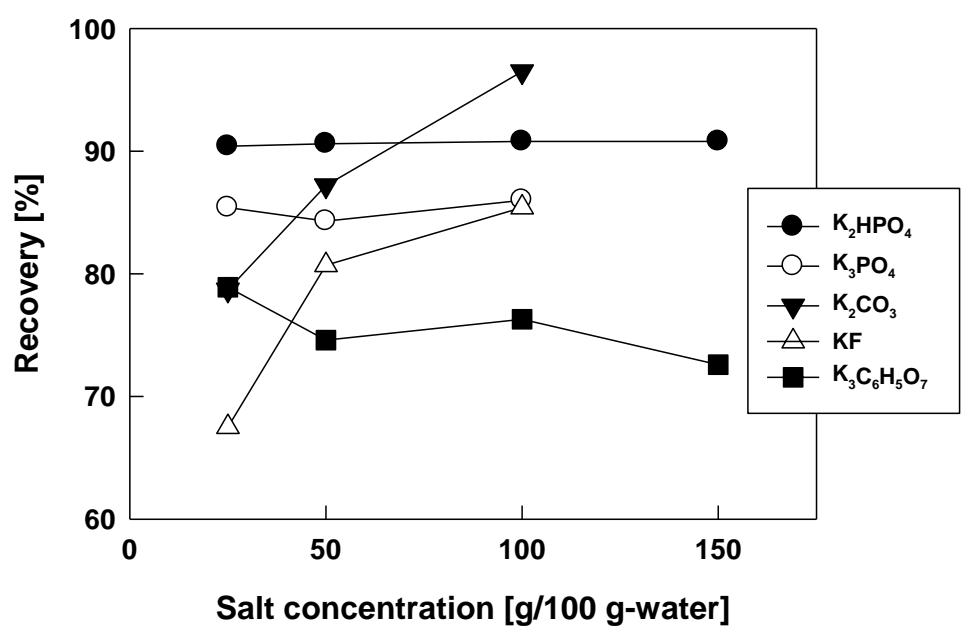

b. THF

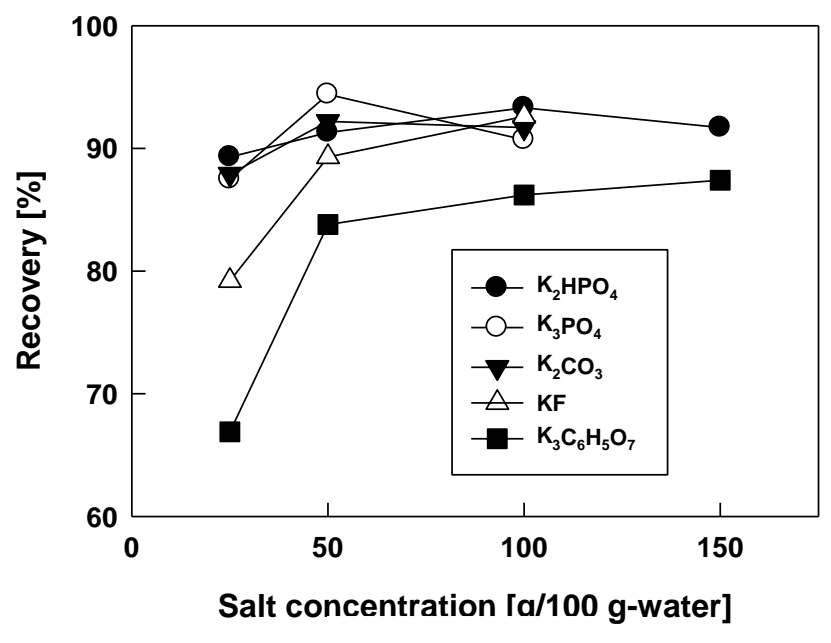

c. 2-ProOH

Figure 3. Recovery ratio of 2,3-BD with the ATPS 


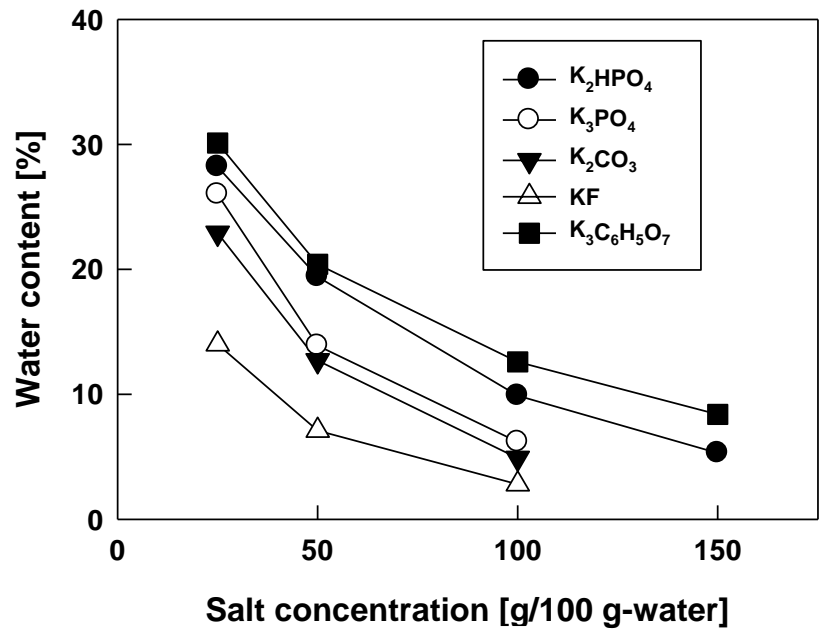

a. $t$-BuOH

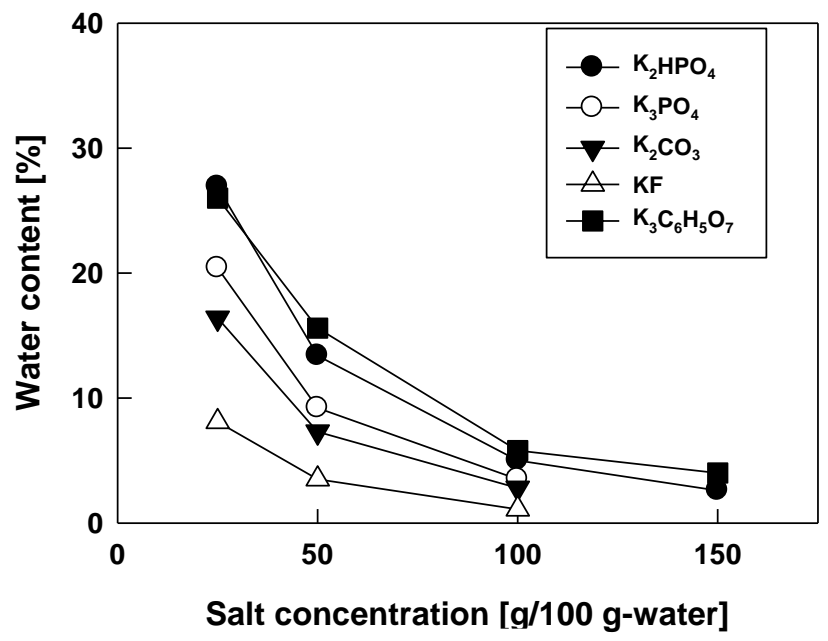

b. THF

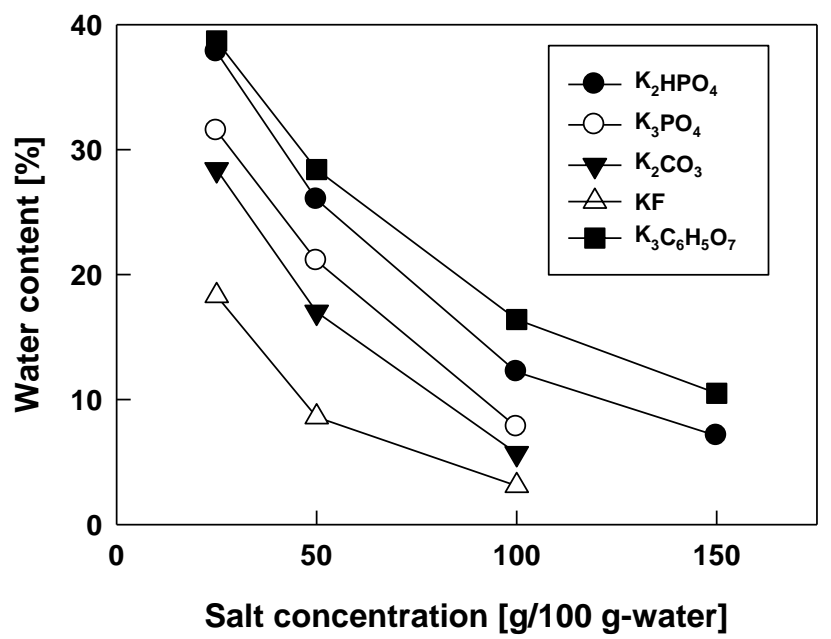

c. 2-ProOH

Figure 4. Water contents in the top phase of the ATPS 


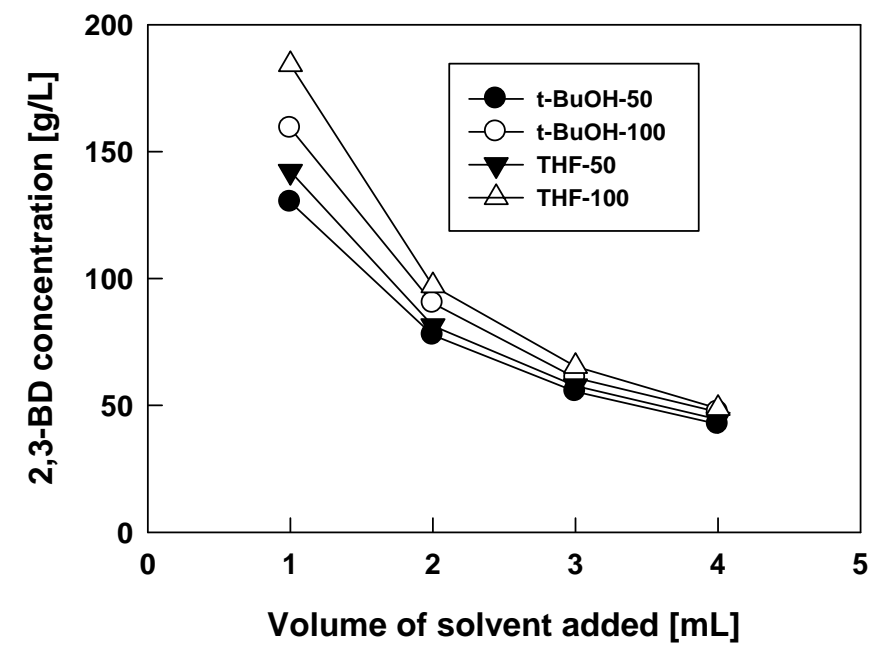

Figure 5. Effect of the volume of water-miscible solvents added on the 2,3-BD concentration in the top phase

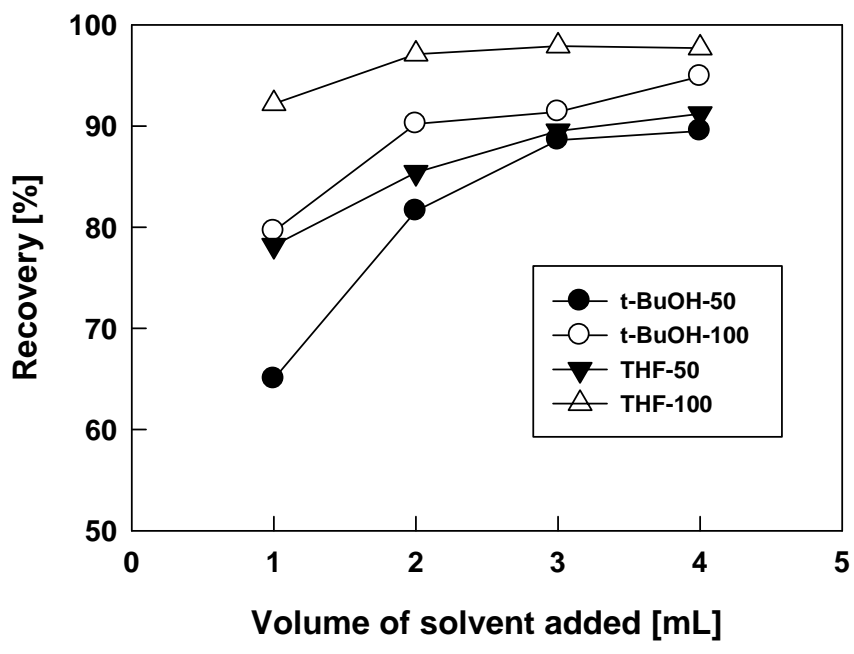

Figure 6. Effect of the volume of water-miscible solvents added on the recovery ratio

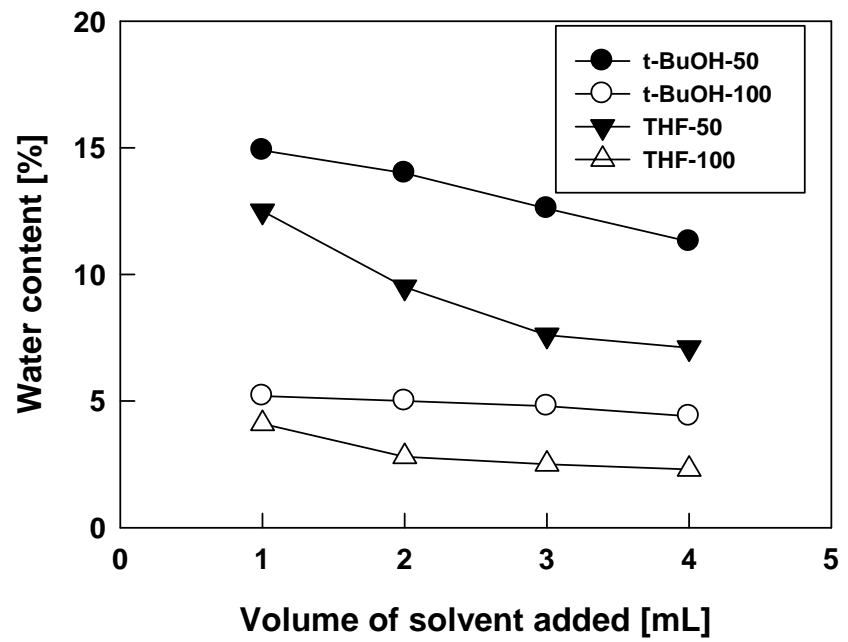

Figure 7. Effect of the volume of water-miscible solvents added on the water contents in the top phase 
In the case of $\mathrm{K}_{2} \mathrm{CO}_{3}$ in the absence of the organic solvent (Table 1), the recovery ratio and water content were $44.9 \%$ and $16.6 \%$, respectively. In the presence of THF, the recovery ratio is more than $90 \%$ and the water content is reduced to $4.1 \%$. Finally we examined the effect of water-immiscible solvents such as 1-pentanol (1-PenOH), 2-methyl-1-propanol (2-M-ProOH) and 1-butanol (1-BuOH) on the extraction of 2,3-BD as shown in Figure 8. The recovery ratios from Figure 8 were within $35 \sim 45 \%$, suggesting that the presence of a hydrophilic solvent is essential for obtaining high recovery of 2,3-BD using salting-out extraction.

\section{Conclusion}

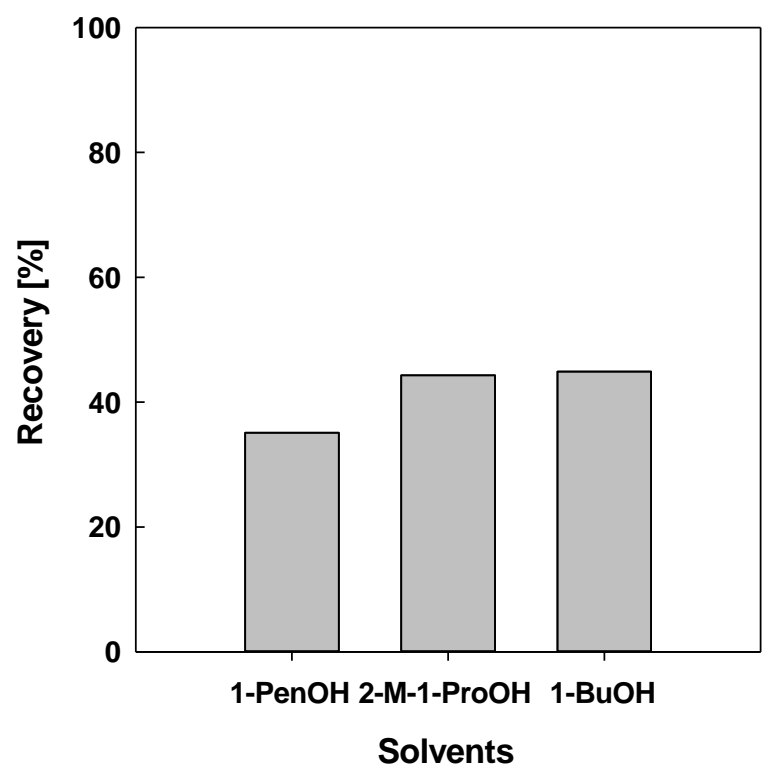

Figure 8. Extraction of 2,3-BD using hydrophobic solvents (Initial 2,3-BD concentration: $50 \mathrm{~g} / \mathrm{L})$

In this study, aqueous two phase systems composed of water-miscible solvents and salts were used to extract 2,3-butanediol from a model solution. The phase separation abilities of water-miscible solvents and the salting-out abilities of salts were evaluated by the difference in the binodal curves and salting-out of 2,3-butanediol. $t$-Butanol and tetrahydrofuran showed high phase separation abilities, and potassium carbonate showed a high salting-out ability. The concentration in the top phase and recovery ratio of 2,3-butanediol reached $184.3 \mathrm{~g} / \mathrm{L}$ and $92.2 \%$, respectively, when the system was composed of THF and potassium carbonate. Presence of a hydrophilic solvent is found to be essential for obtaining high recovery of 2,3-BD using salting-out extraction. This process showed the possibility to provide a simple and economical process for the separation of 2,3-butanediol from fermentation broth.

\section{Acknowledgement}

This work was supported by a Grant-in-Aid for Scientific Research (C) (No. 25420813) from the Ministry of Education, Culture, Sports, Science and Technology, Japan.

\section{References}

1) E. Celińska, W. Grajek, Biotechnol. Adv., 27, 715-725 (2009).

2) X. Ji, H. Huang, P. Ouyang, Biotechnol. Adv., 29, 351-364 (2011).

3) Z. L. Xiu, A. P. Zeng, Appl. Microbiol. Biotechnol., 78, 917-926 (2008).

4) S. Jeon, D. Kim, H. Song, H. J. Lee, S. Park, D. Seung, Y. K. Chang, J. Biosci. Bioeng., 117, 464 -470 (2014).

5) M. Anvari, G. Khayati, J. Ind. Microbiol. Biotechnol., 36, 313-317 (2009).

6) P. Shao, A. Kumar, J. Membr. Sci., 329, 160-168 (2009).

7) H. Pahlavanzadeh, G. Khayati, N. Ghaemi, E. Vasheghani-Farahani, Iran J. Chem. Chem. Eng., 31, 
59-63 (2012).

8) Y. Wu, D. Pan, J. Zhu, K. Chen, B. Wu, L. Ji, Fluid Phase Equilibria, 325, 100-104 (2012).

9) M. Matsumoto, A. Kado, T. Shiraki, K. Kondo, K. Yoshizuka, J. Chem. Tech. Biotechnol., 84, 1712-1716 (2009).

10) Y. Li, Y. Wu, J. Zhu, J. Liu, Biotechnol. Bioprocess Eng., 17, 337-345 (2012).

11) Y. Li, J. Zhu, Y. Wu, J. Liu, Korean J. Chem. Eng., 30, 73-81 (2013).

12) Y. Li, J. Zhu, Y. Wu, J. Liu, Korean J. Chem. Eng., 30, 154-159 (2013).

13) Y. Li, Y. Wu, J. Zhu, J. Liu, Y. Shen, J. Saudi Chem. Soc., in press (DOI: 10.1016/j.jscs.2013.02. 005).

14) M. G. Antov, D. M. Pericin, M. G. Dasic, Process Biochem., 41, 232-235 (2006).

15) F. A. Hasmann, V. C. Santos, D. B. Gurpilhares, A. Pessoa Junior, L. Roberto, J. Chem. Tech. Biotechnol., 83, 167-173 (2008).

16) S. Ghosh, T. Swaminathan, Chem. Biochem. Eng. Quarterly, 17, 319-325 (2003).

17) B. Jiang, Z. Li, J. Dai, D. Xhang, Z. Xiu, Process Biochem., 44, 112-117 (2009).

18) L. Sun, B. Jiang, Z. Xiu, Biotechnol. Lett., 31, 371-376 (2009).

19) Z. Li, H. Teng, Z. Xiu, Process Biochem., 45, 731-737 (2010).

20) J. Dai, Y. Zhang, Z. Xiu, Chin. J. Chem. Eng., 19, 682-686 (2011).

21) Y. Wu, K. Chen, J. Zhu, B. Wu, L. Ji, Y. Shen, Can. J. Chem. Eng., 92, 511-514 (2014).

22) Y. Yang, Y. Liu, J. Han, S. Hu, Sep. Sci. Technol., 46, 1283-1288 (2011).

23) N. Hirayama, T. Higo, H. Imura, Anal. Sci., 28, 541-543 (2012). 